\title{
Increased Hypermethylation of Glutathione S-Transferase P1, DNA-Binding Protein Inhibitor, Death Associated Protein Kinase and Paired Box Protein-5 Genes in Triple-Negative Breast Cancer Saudi Females
}

\author{
Mohamed M Hafez ${ }^{1}$, Othman A Al-Shabanah¹, Salim S Al-Rejaie', Naif O Al- \\ Harbi $^{1}$, Zeinab K Hassan ${ }^{2}$, Abdulmalik Alsheikh ${ }^{3}$, Abdurrahman I Al Theyab ${ }^{4}$, \\ Meshan L Aldelemy ${ }^{5}$, Mohamed M Sayed-Ahmed ${ }^{1 *}$
}

\begin{abstract}
Triple negative breast cancer (TNBC) is an aggressive subtype of breast cancer (BC) with higher metastatic rate and both local and systemic recurrence compared to non-TNBC. The generation of reactive oxygen species (ROS) secondary to oxidative stress is associated with DNA damage, chromosomal degradation and alterations of both hypermethylation and hypomethylation of DNA. This study concerns differential methylation of promoter regions in specific groups of genes in TNBC and non-TNBC Saudi females in an effort to understand whether epigenetic events might be involved in breast carcinogenesis, and whether they might be used as markers for Saudi BCs. Methylation of glutathione S-transferase P1 (GSTP1), T-cadherin (CDH13), Paired box protein 5 (PAX5), death associated protein kinase (DAPK), twist-related protein (TWIST), DNA-binding protein inhibitor (ID4), High In Normal-1 (HIN-1), cyclin-dependent kinase inhibitor 2A (p16), cyclin D2 and retinoic acid receptor- $\beta$ (RARß1) genes was analyzed by methylation specific polymerase chain reaction (MSP) in 200 archival formalinfixed paraffin embedded BC tissues divided into 3 groups; benign breast tissues (20), TNBC (80) and non-TNBC (100). The relationships between methylation status, and clinical and pathological characteristics of patients and tumors were assessed. Higher frequencies of GSTP1, ID4, TWIST, DAPK, PAX5 and HIN-1 hypermethylation were found in TNBC than in non-TNBC. Hypermethylation of GSTP1, CDH13, ID4, DAPK, HIN-1 and PAX5 increased with tumor grade increasing. Other statistically significant correlations were identified with studied genes. Data from this study suggest that increased hypermethylation of GSTP1, ID4, TWIST, DAPK, PAX5 and HIN-1 genes in TNBC than in non-TNBC can act as useful biomarker for BCs in the Saudi population. The higher frequency of specific hypermethylated genes paralleling tumor grade, size and lymph node involvement suggests contributions to breast cancer initiation and progression.
\end{abstract}

Keywords: Breast cancer - TNBC - Non-TNBC - oxidative stress - DNA methylation - Saudi Arabia

Asian Pac J Cancer Prev, 16 (2), 541-549

\section{Introduction}

Breast cancer (BC) is the most common malignancy among females worldwide and represents $22 \%$ of all newly diagnosed female cancers annually in Saudi Arabia with $60-80 \%$ of the patients are diagnosed at advanced stage (Al Tamimi et al., 2010; Aboserea et al., 2011). Triple Negative BC (TNBC) is a subtype of BC is characterized by the absence of hormone receptors expression of progesterone (PR), estrogen (ER) and human epidermal growth factor receptor-2 (HER-2) and represents $10-17 \%$ of all BC patients (Yuan et al.,
2014). It is well documented that tumor development requires phenotypic changes associated with initiation, promotion and progression phases carcinogenesis (Vincent and Gatenby, 2008). Genes in each of these phases acquire alterations in their transcriptional activity that are associated either with hypermethylation-induced transcriptional repression such as tumor suppressor genes or hypomethylation-induced activation in oncogenes (Panayiotidis, 2014). Comprehensive gene analyses on $\mathrm{BC}$ tissues discovered the expression profiles of genes and resulted in identification of mRNAs that are up- and down-regulated in breast carcinomas compared to normal

${ }^{1}$ Department of Pharmacology and Toxicology, College of Pharmacy, ${ }^{2}$ Zoology Department, College of Science, ${ }^{3}$ Department of Pathology, ${ }^{4}$ Oncology Division, Department of Internal Medicine, College of Medicine, King Saud University, ${ }^{5}$ King Abdullah International Medical Research Center, P.O. Box, Riyadh, Kingdom of Saudi Arabia*For correspondence: sayedahmedmm@ hotmail.com 
breast tissue (Gypas et al., 2011; Wu et al., 2012). The DNA gene promoter hypermethylation is the major mode of tumor-specific up-down-regulation in number of genes (Kaczmarczyk et al., 2012; Tuononen et al., 2012).

DNA hypermethylation studies in breast carcinoma focused on the methylation status of tumor-related genes in invasive BC compared to normal breast tissue (Gheibi et al., 2012; Sturgeon et al., 2012; Yamamoto et al., 2012). Several studies identified specific genes targets epigenetic including tumor suppressor gene such as P16 (Feng et al., 2010; Askari et al., 2013; Khor et al., 2013), transcription factors such as TWIST, PAX5 and ID4 (Palmisano et al., 2003; Noetzel et al., 2008; Mishra et al., 2010; Cho et al., 2012), receptors such RAR $\beta$ (Flamini et al., 2014), cytokines such HIN-1 (Krop et al., 2001; Dai et al., 2014), cell cycle regulators such as Cyclin D2 (Henrique et al., 2006), adhesion molecules such as CDH13 (Xu et al., 2012), gene associated with DNA apoptosis such as DAPK (Das and Singal, 2004), gene involved in detoxification pathway of xenobiotic such as GSTP1 (Asemi et al., 2012).

These genes helped to explain the molecular detection and pathogenesis of BC as even small amounts of methylated sequences are readily detecTable. As little information is available about DNA methylation status in TNBC, therefore this study investigates the differential methylation of the promoter region in specific group of genes in TNBC and non-TNBC Saudi's females using MSP in an effort to understand the contribution of this epigenetic event in breast carcinogenesis, and whether it can be used as marker. The selected genes, those play a role in development and progression of $\mathrm{BC}$, fall into different groups: genes commonly methylated in $\mathrm{BC}$ (including cyclin D2, CDH13 and RAR $\beta 1, \mathrm{P} 16, \mathrm{HIN}-1)$, genes associated with transcription factors (such as TWIST, PAX5 and ID4), genes associated with DNA apoptosis such as (DAPK) and gene involved in detoxification of xenobiotics (such as GSTP1).

\section{Materials and Methods}

This study was conducted in compliance with Helsinki Declaration and has been approved by the Ethical Committee, College of Medicine, King Saud University. The present study based on 200 Saudi females living in the province of Riyadh, Kingdom of Saudi Arabia, with primary invasive breast cancer whom had undergone surgery from January 2009 to January 2011 (retrospective analysis). Two hundred formalin-fixed paraffin-embedded (FFPE) breast carcinoma tissues were collected from Pathology Department, College of Medicine, King Saud University (135 cases) and Pathology Department, AlShemissy Hospital (65 cases), Riyadh, Saudi Arabia. Inclusion criterion was archived primary breast tumors (T-stage 1-3 invasive ductal carcinoma of NOS type) assessed by immunohistochemistry for expression of ER, PR and HER-2 at the time of diagnosis. Whole tumor sections were examined to carefully review the histological characteristics of each tissue specimen. separate groups. Group 1 (Control): included 20 FFPE benign breast tissues and served as control. Group 2 (nonTNBC): included 100 FFPE samples from non-TNBC patients. Group 3 (TNBC) included 80 FFPE samples from TNBC patients. In non-TNBC patients, the mean age at diagnosis was 48 years (SE 1.12; range 24 to 91 years).

Twenty-two cases were less than 40 years, 46 cases were $40-50$ years and 32 cases were above 50 years. All Non-TNBC cases had invasive ductal carcinoma with 65 cases had grade III, 29 had grade II and 6 had grade I. Moreover, more than $50 \%$ of non-TNBC cases (53) were positive for ER, PR and HER-2-neu, 19 cases were ER and PR negative and HER-2-neu positive, 15 cases were ER and PR positive and HER-2-neu negative and 13 cases were ER and HER-2-neu positive and PR negative. On the other hand, in TNBC patients, the mean age at diagnosis was 42.5 years (SE 1.2; range 28 to 70 years). A total of 36 cases were less than 40 years, 28 cases were $40-50$ years and 16 cases were above 50 years. Regarding the histoloical categories, all TNBC cases had invasive ductal carcinoma with 35 cases had grade III, 36 had grade II and 9 had grad I. Moreover, all TNBC cases (80) were negative for ER, PR and HER-2-neu. These selected characteristics of the patients showed that there is no significant difference between TNBC and Non-TNBC cases regarding the mean age, histological categories and histological grade of the tumors.

\section{DNA extraction and bisulfate treatment}

All the FFPE samples were thin sectioned at $8 \mu \mathrm{m}$ thicknesses using Leica Microtome (Manual Rotary Microtome RM2235). Tissue sections were floated in a DEPC-treated water bath then picked up on clean glass slides and allowed to air dry at $4^{\circ} \mathrm{C}$, after which they were stored at $-20^{\circ} \mathrm{C}$ until used. The composition of the unstained slides from each archival FFPE tissue block studied was confirmed by histopathologic examination of surrounding hematoxylin and eosin ( $\mathrm{H}$ and $\mathrm{E})$-stained sections. For each tumor, the lesion was identified on an initial $\mathrm{H}$ and E-stained section and confirmed to remain on a serial $\mathrm{H}$ and $\mathrm{E}$ section taken following preparation of unstained sections for micro-dissection and nucleic acid extraction.

Hence, the lesion was documented to be present on stained sections taken before and after preparation of the analyzed unstained sections. For DNA extraction, two $8 \mu \mathrm{m}$ tissue sections were examined and selected areas of tumor tissues were removed from the slides using scalpel and placed directly into sterile $2 \mathrm{ml}$ Eppendorf tubes. DNA was extracted after micro-dissection using Recover All total Nucleic Acid Isolation Kit (Ambion, Life Technologies, USA) following the manufacturer instructions. Tissue sections were deparaffinized followed by digestion using buffer and proteases. Nucleic acids were isolated with additive/ethanol mixture followed by transfer to the column and elution. Quantity and quality of extracted DNA as characterized using a UV spectrophotometer (NanoDrop 8000, thermo scientific, USA).

Sodium bisulfite treatment of DNA

Tissue DNA was treated with sodium bisulfate using
Study design, demographic and clinical characteristics A total of 200 FFPE samples were classified into three 
EpiTect Bisulfite Kits (QIAGEN, Germany) according to the manufactures' instructions. This process converts nonmethylated cytosine residues to uracil, whereas methylated cytosines remain unchanged. All solutions were prepared fresh. Briefly $50 \mu \mathrm{l}$ DNA $(1-2 \mu \mathrm{g})$ extract was incubated with $140 \mu \mathrm{l}$ of bisulfite reaction components at room temperature for $5 \mathrm{~min}$ followed by denaturation at $95^{\circ} \mathrm{C}$ for $5 \mathrm{~min}, 60^{\circ} \mathrm{C}$ for $25 \mathrm{~min}, 95^{\circ} \mathrm{C}$ for $5 \mathrm{~min}, 60^{\circ} \mathrm{C}$ for $85 \mathrm{~min}, 95^{\circ} \mathrm{C}$ for $5 \mathrm{~min}$ and finally $60^{\circ} \mathrm{C}$ for $175 \mathrm{~min}$. BL buffer containing $10 \mu \mathrm{g} / \mathrm{ml}$ carrier RNA was mix with bisulfite converted DNA and transfer to EpiTect spin columns. After washing, $20 \mu \mathrm{l}$ of Elution Buffer was added onto the center of each membrane then the DNA was aliquoted and stored until used at $-80^{\circ} \mathrm{C}$.

\section{Methylation-specific polymerase chain reaction (MSP)} using real time $P C R$

CpG islands of CDH13, GSTP1, ID4, p16, TWIST, Cyclin D2, PAX5, DAPK, HIN-1 and RAR $\beta 1$ genes were examined by MSP (TAKARA, BIO INC, Japan). Forward and reverse primers were synthesized (Metabion, Germany) corresponding to the predicted sequence of methylated or unmethylated genomic DNA after sodium bisulfate treatment (Table 1). For reaction, $1 \mu 1$ sodium bisulfitetreated DNA was added to $24 \mu \mathrm{l}$ reaction buffer containing $0.3 \mu \mathrm{M}$ of forward and reverse primers specific to unmethylated and methylated DNA sequences, $1.2 \mu 1$ of MSP enzyme, $0.5 \mu 1$ of 100X SYBRGreen 1 and $1 \mu \mathrm{l}$ of 50X of ROX reference Dye. The cycling conditions were $95^{\circ} \mathrm{C}$ for $5 \mathrm{~min}$, followed by 45 cycles of $98^{\circ} \mathrm{C}$ for $30 \mathrm{sec}, 55^{\circ} \mathrm{C}$ for $30 \mathrm{sec}$ and $72^{\circ} \mathrm{C}$ for $45 \mathrm{sec}$. Universally methylated DNA and unmethylated DNA (CHEMICON International, Temecula, CA, USA) were used as controls for MSP. Following amplification melting curve analysis was performed to identify the presence of primer dimers and analyzed the reaction specificity. MSP products were separated electrophoretically on $3 \%$ agarose. Single band of methylated and/or unmethylated genes were visualized by photo-documentation system (syngene bio imaging, USA) (Figure1).

\section{Statistically analysis}

The exact chi-square test (SPSS, version 15.0) was used to analyze the association between methylation frequencies of all genes and to compare the tumor characteristics (e.g., age, tumor grade, tumor size) in breast cancer groups. $\mathrm{P}$ values $<0.05$ were considered to be statistically significant.

\section{Results}

This study investigates the role of promoter hypermethylation of ten genes (GSTP1, CDH13, RAR $\beta 1$, TWIST, P16, PAX5, ID4, cyclin D2, HIN-1 and DAPK) in TNBC and non-TNBC cases. In the overall cases, 12 (15\%) of TNBC, 13 (13\%) of non-TNBC and $17(85 \%)$ of benign tissues did not show hypermethylation in any of the studied genes. In benign breast tissue, some degree of hypermethylation was detected in four genes (ID4, TWIST, cyclinD2, and DAPK). Using hierarchical clustering, we identified significant similarity in methylation patterns of genes in TNBC and Non-TNBC breast cancer tissues as shown in Figure 2.

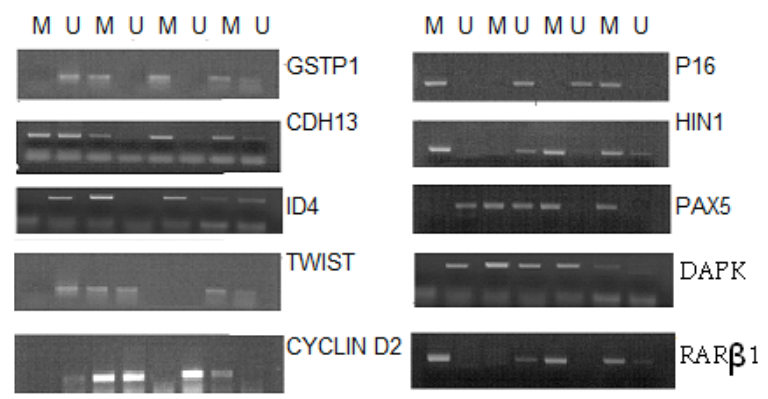

Figure 1. Representative Examples of MethylationSpecific PCR Assays of the Methylated (M) and Unmethylated (U) Genes

Table 1. Primers sequence of Methylated (M) and Unmethylated (U) Genes Used for Methylation Specific Polymerase Chain Reaction

\begin{tabular}{lll}
\hline Gene name & \multicolumn{1}{c}{ Sense Primer } & \multicolumn{1}{c}{ Anti-sense primer } \\
\hline DAPK M & ATT AGA GGT TTT TAA TTG CGT AAC G & AAA AAC GAA ACT TAC AAT AAA CCG A \\
DAPK U & ATT AGA GGT TTT TAA TTG TGT AAT GG & AAA AAC AAA ACT TAC AAT AAA CCA AA \\
ID4 M & TTT ATT TTT TTA TTC GGG TAG TCG A & CAC GTA TAT TTA TAA AAC CGT ACG C \\
ID4 U & TTT ATT TTT TTA TTT GGG TAG TTG A & CAC ATA TAT TTA TAA AAC CAT ACA CC \\
GSTP1 M & GTC GTG ATT TAG TAT TGG GGC & CTA ATA ACG AAA ACT ACG ACG ACG \\
GSTP1 U & TGT GAT TTA GTA TTG GGG TGG & ATA ACA AAA ACT ACA ACA ACA AA \\
HIN-1 M & TAG GGA AGG GGG TAC GGG TTT & CGC TCA CGA CCG TAC CCT AA \\
HIN-1 U & AAG TTT TTG AGG TTT GGG TAG GGA & ACC AAC CTC ACC CACA CTC CTA \\
PAX 5 M & AAA TAA AA ATT CGG TTT GCG TTC & AAA CAT ACG CTT AAA AAT CGC G \\
PAX 5 U & TAA AAA TAA AAA TTT GGT TTG TGT TT & TTA AAA CAT ACA CTT AAA AAT CAC A \\
TWIST M & GTT AGG GTT CGG GGG CGT TGT T & CCG TCG CCT TCC TCC GAC GAA \\
TWIST U & GGT TTG GGG GTG TTG TTT GTA TG & CCC ACC TCC TAA CCA CCC TCC \\
P16 M & TTA TTA GAG GGT GGG GCG GAT CGC & GAC CCC GAA CCG CGA CCG TAA \\
P16 U & TTA TTA GAG GGT GGG GTG GAT TGT & CAA CCC CAA ACC ACA ACC ATA A \\
Cyclin D2 M & TTT GAT TTA AGG ATG CGT TAG AGT ACG & ACT TTC TCC CTA AAA ACC GAC TAC G \\
Cyclin D2 U & TTA AGG ATG TGT TAG AGT ATG TG & AAA CTT TCT CCC TAA AAA CCA ACT ACA AT \\
CDH13 M & GCG GGG TTC GTT TTT CGC GAG & CCG ACT AAA AAC GCC CGA CGA \\
CDH13 U & GTG GGG TTT GTT TTT TGT GAG GT & CCA ACT AAA AAC ACC CAA CAA CA \\
RAR $31 \mathrm{M}$ & AGA ACG CGA GCG ATT CGA GTA G & TAC AAA AAA CCT TCC GAA TAC GTT \\
RAR $31 \mathrm{U}$ & TTG AGA ATG TGA GTG ATT TGA GTA G & TTA CAA AAA ACC TTC CAA ATA CAT TC \\
\hline
\end{tabular}


In TNBC cases, significant hypermethylation $(\mathrm{p}<0.05)$ at high frequencies were observed in GSTP1 $72.5 \%$, CDH13 33.8\% cases (Table 2), ID4 $73.8 \%$, TWIST $48.8 \%$ cases (Table 3), HIN-1 65\% and DAPK 77.5\% cases (Table 4 and Figure 3A) compared to $31 \%, 19 \%$, $43 \%, 34 \%, 42 \%$ and $43 \%$ respectively in non-TNBC (Figure 3B). In benign breast tissues, two cases showed hypermethylation in six out of ten studied genes while the third case showed hypermethylation in 9 genes.

In TNBC, DAPK gene hypermethylation was significantly increased with tumor size from $77.8 \%$ in $<2 \mathrm{~cm}$ to $84.6 \%$ in $>2 \mathrm{~cm}$ compared to $33.3 \%$ and $46.8 \%$ in Non-TNBC respectively. In TNBC, DAPK gene hypermethylation was significantly associated also with grade increasing $77.8 \%$ in grade-I, $69.4 \%$ in grade-II and $85.7 \%$ in grader-III cases compared to $33.3 \%, 44.8 \%$ and $43.1 \%$ respectively in non-TNBC. According to LN status in TNBC, DAPK gene was significant increase from $74.3 \%$ in $\mathrm{LN}$ negative to $80 \%$ in $\mathrm{LN}$ positive compared to $41.2 \%$ and $46.9 \%$ respectively in non-TNBC (Table 4).

ID4 gene hypermethylation was significantly increased with increasing tumor size $84.6 \%$ in $>2 \mathrm{~cm}$ compared to $72.2 \%$ in $<2 \mathrm{~cm}$ in TNBC compared to $46.8 \%$ and $33.3 \%$ respectively in non-TNBC (Table 3). There was significant increase in association with LN status in TNBC $77.8 \%$ in $\mathrm{LN}$ positive and $68.6 \%$ in $\mathrm{LN}$ negative compared to $49.9 \%$ and $41.2 \%$ respectively in non-TNBC. With regard to tumor grade, a significant hypermethylation of ID4 gene $(66.7 \%$ and $80 \%)$ was observed in grade II and III in TNBC compared to Non-TNBC.

GSTP1 gene hypermethylation in TNBC was significantly associated with tumor grade $66.7 \%$ in grade-I, $75 \%$ in grade-II and $71.4 \%$ in grade-III compared to $16.7 \%, 27.6$ and $33.8 \%$ respectively in non-TNBC (Table 2). In relation to LN status, no significant changes were observed in both groups. Concerning tumor size, GSTP1 gene hypermethylation was significantly increased with tumor size in TNBC compared to Non-TNBC.

Cylcin D2 hypermethylation was significantly higher

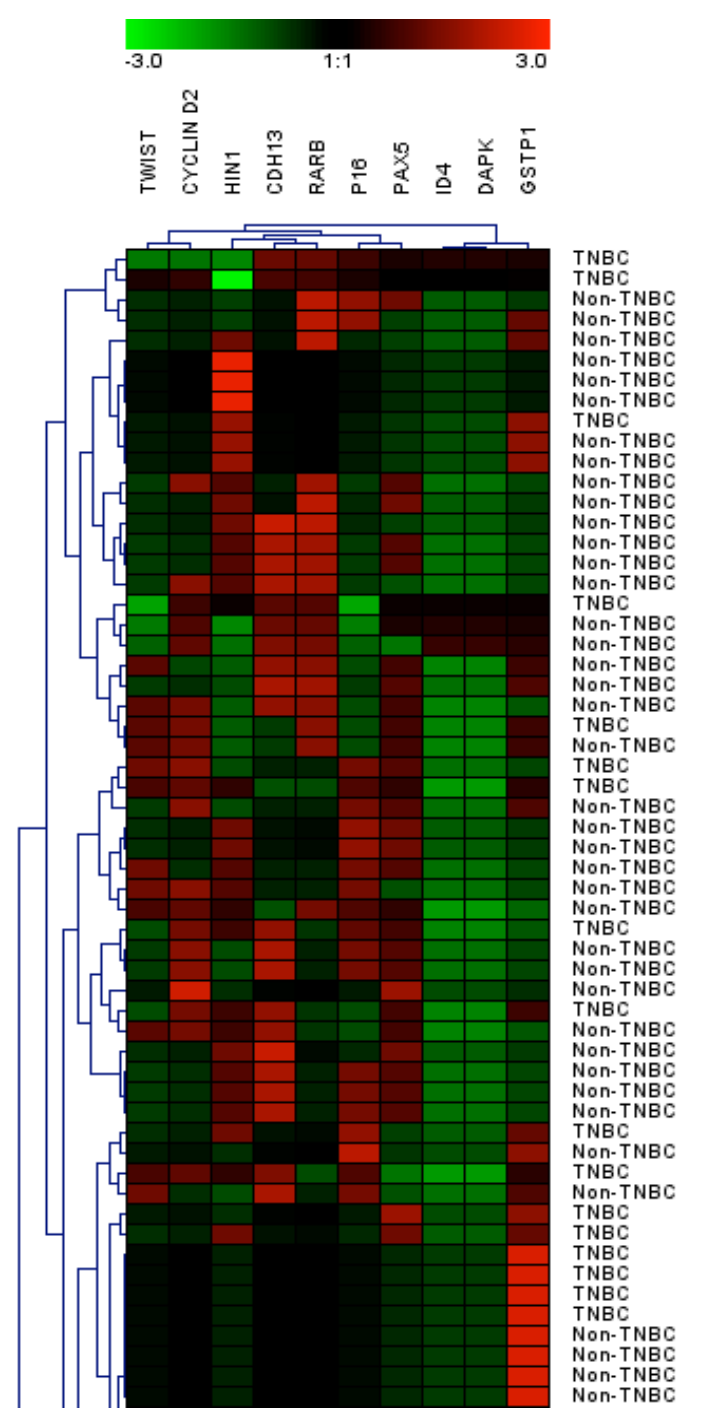

Figure 2. Hierarchical Clustering of the Promoter Hypermethylation of Studied Genes and Breast Cancer Samples. Red represents positive methylation event while green represents a negative methylation event. Clustering was performed using the Genesis program

Table 2. Correlation between Percentage Methylation (M \%) of GSTP1, CDH13, Cyclin D2 and RARß1 Genes and Clinico-pathological Features among Triple Negative and Non-triple Negative Breast Cancer Patients

\begin{tabular}{|c|c|c|c|c|c|c|c|c|c|c|}
\hline \multirow[t]{2}{*}{ Characteristics } & \multicolumn{5}{|c|}{ TNBC } & \multicolumn{5}{|c|}{ Non-TNBC } \\
\hline & $\mathrm{N}$ & GSTP1 & CDH13 & Cyclin D2 & RAR $\beta 1$ & $\mathrm{~N}$ & GSTP1 & CDH13 & Cyclin D2 & RAR $\beta 1$ \\
\hline M \% & 80 & $72.5^{*}$ & $33.8^{*}$ & 36.3 & 25 & 100 & 31 & 19 & 33 & 26 \\
\hline \multicolumn{11}{|l|}{ Age (year): } \\
\hline$<40$ years & 36 & 69.4 & 41.7 & 44.4 & 38.9 & 22 & 18.2 & 31.8 & 27.3 & 36.4 \\
\hline $41-50$ years & 28 & 78.6 & 21.4 & 39.3 & 14.3 & 46 & 37 & 15.2 & 37 & 23.9 \\
\hline$>50$ years & 16 & 68.8 & 37.5 & 12.5 & 12.5 & 32 & 31.2 & 15.6 & 31.2 & 21.9 \\
\hline \multicolumn{11}{|l|}{ Tumor Grade: } \\
\hline I & 9 & $66.7 *$ & 0 & $33.3 *$ & 22.2 & 6 & 16.7 & 16.7 & 83.3 & 16.7 \\
\hline II & 36 & $75 *$ & 33.3 & 36.1 & 25 & 29 & 27.6 & 17.2 & 27.6 & 27.6 \\
\hline III & 35 & $71.4^{*}$ & $42.9^{*}$ & 37.1 & 25.7 & 65 & 33.8 & 20 & 37.1 & 26.2 \\
\hline \multicolumn{11}{|c|}{ Lymphnode status: } \\
\hline positive & 45 & $71.1 *$ & 31.1 & 37.8 & 28.9 & 32 & 28.1 & 21.9 & 21.9 & 21.9 \\
\hline negative & 35 & $74.3^{*}$ & $37.1 *$ & 34.3 & 20 & 68 & 32.4 & 17.6 & 38.2 & 27.9 \\
\hline \multicolumn{11}{|l|}{ Tumor size: } \\
\hline Unknown & 36 & 69.4 & 33.3 & 41.7 & 22.2 & 14 & 57.1 & 21.4 & 28.6 & 14.3 \\
\hline$<2 \mathrm{~cm}$ & 18 & $72.2 *$ & 38.9 & 33.3 & 16.7 & 24 & 12.5 & 16.7 & 29.2 & 37.5 \\
\hline$>2 \mathrm{~cm}$ & 26 & $76.9 *$ & 30.8 & 30.8 & 34.6 & 62 & 32.3 & 19.4 & 35.5 & 24.2 \\
\hline
\end{tabular}

Data are presented as percentage methylation $(\mathrm{M} \%), \mathrm{n}=100$ and 80 for Non-TNBC and TNBC groups, respectively. $*$ indicate significant change from Non-TNBC, using exact chi-square test (SPSS, version 15.0). P values $\leq 0.05$ were considered statistically significant 
in tumor grade $\mathrm{I}(83 \%)$ in non-TNBC compared to $33.3 \%$ in TNBC groups. In both groups, there was no association between hypermethylation of cyclin D2 and tumor size. According to LN status, in non-TNBC was $21.9 \%$ in $\mathrm{LN}$ positive compared to $38.2 \%$ in $\mathrm{LN}$ negative while in TNBC no association was observed (Table 2).
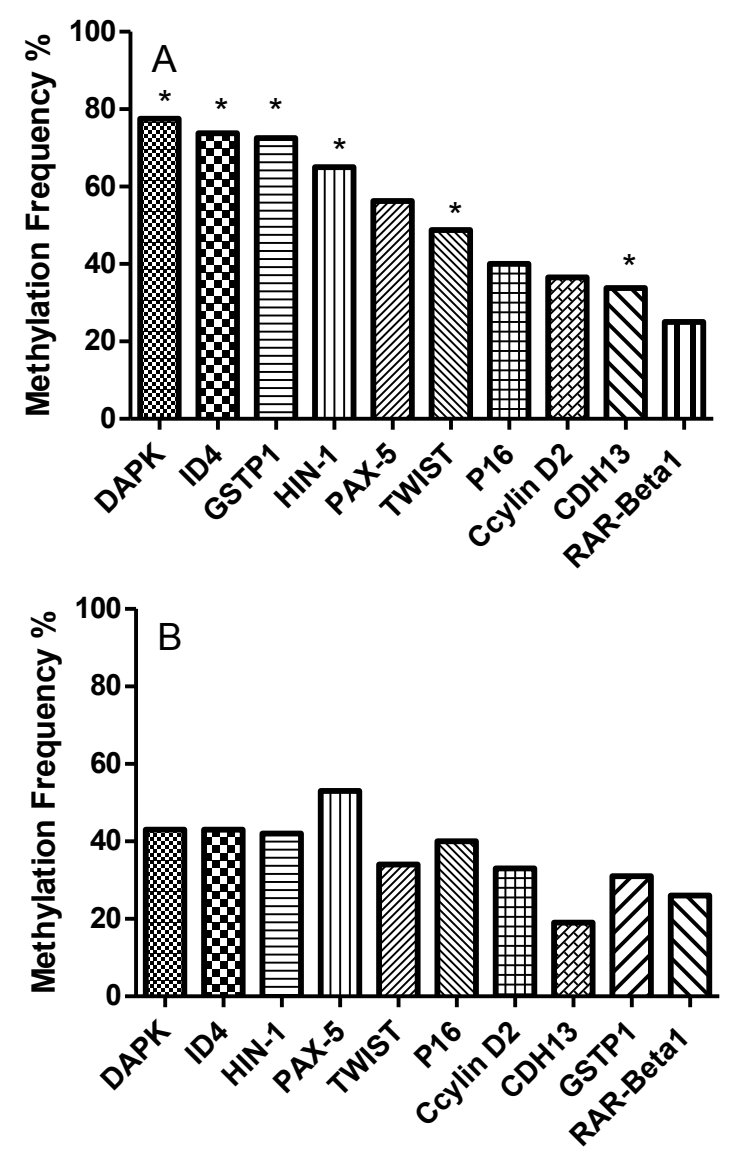

Figure 3. Percentage of Methylation Frequency of All Investigated Genes among Triple Negative A) and Non-triple negative B) breast cancer cases. * indicates significant change from Non-TNBC
CDH13 gene hypermethylation was insignificantly associated with grade increasing in TNBC grade-I $0 \%$, grade-II $33.3 \%$ and grade-III $42.9 \%$ compared to $16.7 \%$, $17.2 \%$ and $20 \%$ in non-TNBC and associated with tumor size, $<2 \mathrm{~cm}(38.9 \%)$ compared to $30.8 \%$ in $>2 \mathrm{~cm}$ compared to $16.7 \%$ and $19.4 \%$ respectively in non-TNBC. According to LN status, there was statistically significant was observed in LN negative in TNBC (37.1\%) compared to $17.6 \%$ in non-TNBC (Table 2).

RAR $\beta 1$ gene hypermethylation was insignificantly increased with tumor size, in TNBC was $34.6 \%$ in tumor size $>2 \mathrm{~cm}$ and $16.7 \%$ in those $<2 \mathrm{~cm}$ compared to $24.2 \%$ and $37.5 \%$ respectively in non-TNBC. There was a decrease in this gene associated with $\mathrm{LN}$ status by $28.9 \%$ in $\mathrm{LN}$ positive and $20 \%$ in $\mathrm{LN}$ negative in TNBC compared to $21.9 \%$ and $27.9 \%$ respectively in non-TNBC (Table 2).

PAX5 gene hypermethylation was decreased with tumor size $<2 \mathrm{~cm}$ and $>2 \mathrm{~cm}$ from $61.1 \%$ to $53.8 \%$ in TNBC and increased in non-TNBC from $41.7 \%$ to $58.1 \%$ respectively. In TNBC, hypermethylation of PAX5 was associated with grade increasing $55.6 \%$ in grade-I, $52.8 \%$ in grade-II and $60 \%$ in grade-III compared to $66.7 \%$, $62.1 \%$ and $47.7 \%$ respectively in non-TNBC. In relation to $\mathrm{LN}$ status, in TNBC hypermethylation was increased from $51.4 \%$ in $\mathrm{LN}$ negative to $60 \%$ in positive $\mathrm{LN}$ and decreased from $59.4 \%$ to $50 \%$ in non-TNBC, but this differences were statistically insignificant (Table 3).

TWIST gene hypermethylation was observed with high frequency in grade-I $55.6 \%$ in TNBC compared to $50 \%$ in non-TNBC. In addition, hypermethylation of TWIST gene was insignificantly increased with increasing tumor size, $<2 \mathrm{~cm} 33.3 \%$ and $>2 \mathrm{~cm} 50 \%$ in TNBC compared to $54.2 \%$ and $32.3 \%$ in TNBC respectively (Table 3 ).

HIN-1 gene hypermethylation was significantly increased in TNBC by $65.7 \%$ in grade-III compared to $33.8 \%$ in non-TNBC. In TNBC, HIN-1 gene hypermethylation was increased significantly $74.3 \%$ in LN negative and insignificantly $57.8 \%$ in LN positive

Table 3. Correlation between Percentage Methylation (M \%) of ID4, TWIST and PAX5 Genes and Clinicopathological Features among Triple Negative and Non-triple Negative Breast Cancer Patients

\begin{tabular}{|c|c|c|c|c|c|c|c|c|}
\hline \multirow[t]{2}{*}{ Characteristics } & \multicolumn{4}{|c|}{ TNBC } & \multicolumn{4}{|c|}{ Non-TNBC } \\
\hline & $\mathrm{N}$ & ID4 & TWIST & PAX5 & $\mathrm{N}$ & ID4 & TWIST & PAX5 \\
\hline M \% & 80 & $73.8^{*}$ & $48.8^{*}$ & 56.3 & 100 & 43 & 34 & 53 \\
\hline \multicolumn{9}{|l|}{ Age (year): } \\
\hline$<40$ years & 36 & 80.6 & 55.6 & 50 & 22 & 36.4 & 27.3 & 77.3 \\
\hline $41-50$ years & 28 & 75 & 50 & 64.3 & 46 & 54.3 & 32.6 & 50 \\
\hline$>50$ years & 16 & 56.3 & 31.3 & 56.3 & 32 & 31.2 & 31.2 & 40.6 \\
\hline \multicolumn{9}{|l|}{ Grade Tumor: } \\
\hline I & 9 & 77.8 & 55.6 & 55.6 & 6 & 33.3 & 50 & 66.7 \\
\hline II & 36 & $66.7 *$ & 47.2 & 52.8 & 29 & 44.8 & 27.6 & 62.1 \\
\hline III & 35 & $80 *$ & 48.6 & 60 & 65 & 56 & 35.4 & 47.7 \\
\hline \multicolumn{9}{|c|}{ Lymphnode status: } \\
\hline positive & 45 & $77.8 *$ & $53.3 *$ & 60 & 32 & 46.9 & 25 & 59.4 \\
\hline negative & 35 & $68.6^{*}$ & 42.9 & 51.4 & 68 & 41.2 & 38.2 & 50 \\
\hline \multicolumn{9}{|l|}{ Tumor size: } \\
\hline Unknown & 36 & 66.7 & 55.6 & 55.6 & 14 & 42.9 & 7.1 & 50 \\
\hline$<2 \mathrm{~cm}$ & 18 & $72.2^{*}$ & 33.3 & 61.1 & 24 & 33.3 & 54.2 & 41.7 \\
\hline$>2 \mathrm{~cm}$ & 26 & $84.6 *$ & 50 & 53.8 & 62 & 46.8 & 32.3 & 58.1 \\
\hline
\end{tabular}

Data are presented as percentage methylation (M \%), n=100 and 80 for Non-TNBC and TNBC groups, respectively; * indicate significant change from Non-TNBC, using exact chi-square test (SPSS, version 15.0 ). P values $\leq 0.05$ were considered statistically significant 
Table 4. Correlation between Percentage Methylation (M\%) of P16 and HIN-1 genes and Clinico-pathological Features among Triple Negative and Non-triple Negative Breast Cancer Patients

\begin{tabular}{|c|c|c|c|c|c|c|c|c|}
\hline \multirow[t]{2}{*}{ Characteristics } & \multicolumn{4}{|c|}{ TNBC } & \multicolumn{4}{|c|}{ Non-TNBC } \\
\hline & $\mathrm{N}$ & p16 & HIN1 & DAPK & $\mathrm{N}$ & p16 & HIN1 & DAPK \\
\hline $\mathrm{M} \%$ & 80 & 40 & $65^{*}$ & $77.5^{*}$ & 100 & 40 & 42 & 43 \\
\hline \multicolumn{9}{|l|}{ Age (year): } \\
\hline$<40$ years & 36 & 47.2 & 58.3 & $80.6^{*}$ & 22 & 40.9 & 54.5 & 36.4 \\
\hline $41-50$ years & 28 & 39.3 & $71.4 *$ & 78.6 & 46 & 43.5 & 43.5 & 54.3 \\
\hline$>50$ years & 16 & 25 & $68.8^{*}$ & $68.8 *$ & 32 & 34.4 & 31.2 & 31.2 \\
\hline \multicolumn{9}{|l|}{ Tumor Grade: } \\
\hline I & 9 & 22.2 & 55.6 & $77.8^{*}$ & 6 & 33.3 & 33.3 & 33.3 \\
\hline II & 36 & 47.2 & 66.7 & $69.4^{*}$ & 29 & 41.4 & 62.1 & 44.8 \\
\hline III & 35 & 37.1 & $65.7 *$ & $85.7 *$ & 65 & 40 & 33.8 & 43.1 \\
\hline \multicolumn{9}{|c|}{ Lymphnode status: } \\
\hline positive & 45 & 35.6 & 57.8 & $80 *$ & 32 & 46.9 & 46.9 & 46.9 \\
\hline negative & 35 & 45.7 & $74.3^{*}$ & $74.3 *$ & 68 & 36.8 & 39.7 & 41.2 \\
\hline \multicolumn{9}{|l|}{ Tumor size: } \\
\hline Unknown & 36 & 41.7 & 66.7 & 72.2 & 14 & 50 & 42.9 & 42.9 \\
\hline$<2 \mathrm{~cm}$ & 18 & 27.8 & 66.7 & $77.8 *$ & 24 & 33.3 & 41.7 & 33.3 \\
\hline$>2 \mathrm{~cm}$ & 26 & 46.2 & 61.5 & $84.6^{*}$ & 62 & 40.3 & 41.9 & 46.8 \\
\hline
\end{tabular}

*Data are presented as percentage methylation $(\mathrm{M} \%), \mathrm{n}=100$ and 80 for Non-TNBC and TNBC groups, respectively. * indicate significant change from Non-TNBC, using exact chi-square test (SPSS, version 15.0). P values $\leq 0.05$ were considered to be statistically significant

compared to $36.8 \%$ and $46.9 \%$, respectively in NonTNBC (Table 4).

P16 hypermethylation was insignificantly increased in TNBC with tumor size from $27.8 \%$ in tumor size $<2 \mathrm{~cm}$ to $46.2 \%$ in $>2 \mathrm{~cm}$ and from $33.3 \%$ to $40.3 \%$ respectively in non-TNBC. In TNBC, P16 hypermethylation was associated with grade increasing $22.2 \%$ in grade-I compared to $47.2 \%$ in grade-II. With regard to $\mathrm{LN}$ status, in non-TNBC P16 hypermethylation was $36.8 \%$ in LN negative and $46.9 \%$ in LN positive while in TNBC no association was observed (Table 4).

\section{Discussion}

Although several studies have demonstrated that DNA hypermethylation plays an important role in breast carcinogenesis (Cho et al., 2009; Tan et al., 2012), little information is available about DNA methylation status in TNBC.Accordingly, this study investigates the differential methylation of the promoter region in specific group of genes in TNBC and Non-TNBC Saudi's females. Our results detected overall higher methylation frequencies of GSTP1, HIN-1, TWIST, ID4, PAX5 and DAPK genes in TNBC compared to non-TNBC. The promoter hypermethylation of these genes can be used as tumorspecific biomarker in TNBC Saudi's patients.

Death associated protein kinase (DAPK) gene is a positive mediator for programmed cell death induced by $\gamma$-interferon (Suijkerbuijk et al., 2010). The loss of DAPK gene expression was associated with aggressive and metastatic phenotype in many tumor types primarily by promoter hypermethylation (Suijkerbuijk et al., 2010). In the present study, DAPK gene was hypermethylated at highest frequencies in TNBC compared to non-TNBC. In addition, we found strong and higher association between DAPK hypermethylation and tumor grade and size in both TNBC and non-TNBC. Similarly in patients with head and neck cancer, Sanchez-Cespedes et al. (2000) observed an association between DAPK methylation and tumor size (Sanchez-Cespedes et al., 2000). They also found frequently lost in the expression of DAPK gene and protein in human cancer often as a result of silencing by DNA methylation. Similarly, higher hypermethylation of DAPK gene was observed in more advanced stage of cervical cancer (Narayan et al., 2003). Accordingly, one can anticipate that this hypermethylation of DAPK gene with the consequent lose of its expression may play a role in breast cancerinogenesis.

ID4 gene has regulative functions for cell differentiation and growth. Inactivation of ID4 gene via promoter hypermethylation has been shown in human tumors such as breast cancer (Noetzel et al., 2008). Data presented here demonstrated differential increase of ID4 hypermethylation in TNBC than Non-TNBC cases. In addition, the incidence of ID4 hypermethylation was increased with increasing tumor size and the number of LN positive in both TNBC and non-TNBC cases. Accordingly, our results suggested that hypermethylation of ID4 as a potential tumor suppressive gene may play an important role in BC development and can be used as a genetic marker for prediction of early metastasis that could explain the aggressiveness of TNBC compared to non-TNBC. Our results are consistent with the data presented by Umetani et al. which have demonstrated a significant lower mRNA level of ID4 in primary breast cancer specimens and indicated that the ID4 transcription was inactivated by promoter hypermethylation in clinical breast cancer specimens (Umetani et al., 2005).

Glutathione S-transferase P1 (GSTP1) is a polymorphic gene encoding active, functionally different variant proteins that are thought to function in xenobiotic metabolism and play a role in susceptibility to cancer, and other diseases. As different types of diet has been implicated in breast cancer, the loss of GSTP1 secondary to hypermethylation lead to impaired of cellular defenses leading to increasing genome damage and cancer 
development (Wang et al., 2014). In our study, high frequency of GSTP1 hypermethylation was significant associated with TNBC. This finding is important as GST gene is a family of enzymes that detoxify hydrophobic electrophiles, which include carcinogens that have been occupied with variety of cancers (Wang et al., 2014). The detection of GSTP1 hypermethylation was not correlated with other clinical parameters such as age, tumor size and LN status which are consistent with previous study (Jentzmik et al., 2012). Hypermethylation of GSTP1 with high frequency in different tumor grade was pathologically correlated with early stage of cancer.

In human breast cancer, hypermethylation of tumor suppressor gene is clearly observed. HIN-1 gene, a putative cytokine, is down-regulated in breast cancer tissues by promoter hypermethylation (Park et al., 2011). The present study showed increased in the frequency of HIN-1 gene hypermethylation in TNBC than Non-TNBC patients with higher incidence in $\mathrm{LN}$ positive in both groups. Other study found frequent methylation of $\mathrm{HIN}-1$, CDH13 and RAR $\beta 2$ genes in primary breast cancer and in metastatic LN but not in normal breast tissues (Feng et al., 2010). Our results showed higher hypermethylation of HIN-1 in both tumor grades II and III which indicates that HIN-1 gene is epigenetically at advanced stage in both TNBC and Non-TNBC and can be used as a good prognostic markers for Saudi's patients. Other found significant high frequency of HIN-1 gene promoter hypermethylation in tumor at an advanced stage compared to those at early stages (Lee et al., 2010).

PAX5 gene plays an important role in cell differentiation and embryonic development (Palmisano et al., 2003). In the current study, high non-significant frequency of PAX5 hypermethylation was observed in association with tumor grade, size and LN. In breast tumor, PAX5 gene hypermethylation is responsible for gene silencing. Moelans et al. found an association between PAX5 and tumor grade but no association with LN status (Moelans et al., 2011). In addition, PAX5 gene has been implicated in the pathogenesis of small lymphocytic lymphoma cancer and advanced-stage glioblastoma (O'Brien et al., 2011). DNA methylation was linked to the transcriptional silencing of PAX5 genes in murine myeloma cells (Danbara et al., 2002).

TWIST gene belongs to the basic-helix-loop-helix family of an antiapoptotic and prometastatic transcription factors (Sung et al., 2011). TWIST gene can act as oncogene that inhibits apoptosis in a p53-independent manner and may be important to the biology of tumor distant metastasis (Escobar-Cabrera Je, 2013). It may also alter cellular growth via its effects upon chromatin structure (Hamamori et al. 1999). TWIST hypermethylation was increased with tumor size increasing in TNBC and decreased in Non-TNBC. Other study suggested that there is no association between the tumor size and TWIST gene in invasive breast carcinoma patients (Bae et al., 2005).

P16 is a well-documented tumor suppressor gene in many tumors (Peurala et al., 2013). Promoter methylation of P16 has been reported in different studies (Demokan et al., 2012; Jha et al., 2012; Khor et al., 2013; Wani et al., 2013). In the present study, P16 hypermethylation showed insignificant increase in both TNBC and Non-TNBC and was associated with tumor grade increasing in TNBC. Similarly, Radpour et al. observed a correlation between P16 gene hypermethylation and stage of cancer (Radpour et al., 2011). We suggested that P16 gene may not only play a significant role in early stage of $\mathrm{BC}$ but also in cancer progression. This is clear in non-TNBC in which the P16 hypermethylation was associated with LN status and was insignificantly increased in tumor size. Other study by Zhao et al. found no correlation between size of cancer, LN metastasis and methyaltion rate of p16 gene (Zhao et al., 2010).

Cyclin D2, a member of D-type cyclins, is implicated in cell cycle regulation, differentiation and malignant transformation (Sakuma et al., 2007). In the current study, Cyclin D2 gene promoter is hypermethylated higher in both $\mathrm{BC}$ groups than in benign breast tissue and it was significantly increased with tumor grade in non-TNBC. Previous findings on invasive lobular carcinoma (ILC) and invasive ductal carcinoma (IDC) showed a trend towards increased Cyclin D2 methylation progressing from lowgrade ductal in situ (DCIS) breast cancers grades-I and -II $27 \%$ to high-grade DCIS $39 \%$ to IDC $52 \%$ (Evron et al., 2001; Lehmann et al., 2002).

CDH13 gene can act as a tumor suppressor gene and its expression is decreased in invasive carcinomas resulting in decreasing cell-cell adhesion enhancing tumor progression and invasion (Ellmann et al., 2012). We reported a significant increase in CDH13 gene hypermethylation in TNBC compared to Non-TNBC and was increased in $\mathrm{LN}$ positive TNBC cases. This increase is due to the association between this gene with the hormone receptor (Feng et al., 2007). Similarly, more frequently CDH13 hypermethylation was observed in invasive adenoma than in non-invasive adenoma and was associated with high grade (Kornegoor et al., 2012). Also, in breast cancer cell line higher hypermethylation of CDH13 was found and rare in non-malignant and control tissues (Jung et al., 2013). Therefore, the suppression of CDH13 gene by methylation is associated with tumor formation and can be used as a marker for breast cancer development and invasion. RAR $\beta 1$ is involved in regulation of cellular growth inhibition and apoptosis. Our study established that RAR $\beta 1$ promoter is frequently hypermethylated in both TNBC and non-TNBC. RAR $\beta 1$ gene mediates the growth inhibitory effects of retinoic acids in breast cancer cells and also several studies established RAR $\beta 1$ gene promoter hypermethylation in breast carcinoma (Raffo et al., 2000; Weiwei et al., 2007). Hypermethylation of RAR $\beta$ was correlated with HER2-positive tumors and with poor prognosis (Mehrotra et al., 2004). RAR $\beta$ gene can act as a tumor suppressor gene and loss of its expression is found in variety of tumors (Liu et al., 2011). These data provide evidence that hypermethylation is the major mechanism involved in RAR $\beta$ gene silencing which resulted in impaired RAR $\beta$ function during BC development. In conclusion, data from this study suggest that the epigenetic event clearly observed in TNBC and NonTNBC patients might be used as marker for Saudi's BC. Moreover, this study highlights the promotor methylation of specific genes involved in different molecular pathways, 
detoxification, proapoptotic gene that potentially inhibits metastasis, tissue differentiation, regulate expression of tissue-specific genes, tumor suppressor gene and transcription factor. Information from this study may be useful in epigenetic therapy for breast cancer.

\section{Acknowledgements}

Authors thank the Deanship of Scientific Research at $\mathrm{KSU}$ for funding this work through the research group project no. RGP-VPP-142.

\section{References}

Aboserea M, Abdelgawad Mwafik W (2011). Early detection of breast cancer among females at fakous district, sharqia governorate, egypt. Life Science J, 8, 196-203.

Al Tamimi DM, Shawarby MA, Ahmed A, et al (2010). Protein expression profile and prevalence pattern of the molecular classes of breast cancer--a Saudi population based study. BMC Cancer, 10, 223.

Asemi Z, Jazayeri S, Najafi M, et al (2012). Effect of daily consumption of probiotic yogurt on oxidative stress in pregnant women: a randomized controlled clinical trial. Ann Nutr Metab, 60, 62-8.

Askari M, Sobti RC, Nikbakht M, et al (2013). Promoter hypermethylation of tumour suppressor genes (p14/ARF and p16/INK4a): case-control study in North Indian population. Mol Biol Rep, 40, 4921-8.

Bae YK, Shim YR, Choi JH, et al (2005). Gene promoter hypermethylation in tumors and plasma of breast cancer patients. Cancer Res Treat, 37, 233-40.

Cho NY, Kim JH, Moon KC, et al (2009). Genomic hypomethylation and $\mathrm{CpG}$ island hypermethylation in prostatic intraepithelial neoplasm. Virchows Arch, 454, 17-23.

Cho YH, Shen J, Gammon MD, et al (2012). Prognostic significance of gene-specific promoter hypermethylation in breast cancer patients. Breast Cancer Res Treat, 131, 197-205.

Dai D, Dong XH, Cheng ST, et al (2014). Aberrant promoter methylation of HIN-1 gene may contribute to the pathogenesis of breast cancer: a meta-analysis. Tumour Biol, 35, 8209-16.

Danbara M, Kameyama K, Higashihara M, et al (2002). DNA methylation dominates transcriptional silencing of Pax5 in terminally differentiated B cell lines. Mol Immunol, 38, 1161-6.

Das PMSingal R (2004). DNA methylation and cancer. J Clin Oncol, 22, 4632-42.

Demokan S, Chuang A, Suoglu Y, et al (2012). Promoter methylation and loss of p16(INK4a) gene expression in head and neck cancer. Head Neck, 34, 1470-5.

Ellmann L, Joshi MB, Resink TJ, et al (2012). BRN2 is a transcriptional repressor of CDH13 (T-cadherin) in melanoma cells. Lab Invest, 92, 1788-800.

Escobar-Cabrera Je BSLaGAG (2013). The role of transcription factor twist in cancer cells. J Genet Syndr Gene Ther 4, 1-7.

Evron E, Umbricht CB, Korz D, et al (2001). Loss of cyclin D2 expression in the majority of breast cancers is associated with promoter hypermethylation. Cancer Res, 61, 2782-7.

Feng W, Orlandi R, Zhao N, et al (2010). Tumor suppressor genes are frequently methylated in lymph node metastases of breast cancers. BMC Cancer, 10, 378 .

Feng W, Shen L, Wen S, et al (2007). Correlation between CpG methylation profiles and hormone receptor status in breast cancers. Breast Cancer Res, 9, 57.
Flamini MI, Gauna GV, Sottile ML, et al (2014). Retinoic acid reduces migration of human breast cancer cells: role of retinoic acid receptor beta. $J$ Cell Mol Med, 18, 1113-3.

Gheibi A, Kazemi M, Baradaran A, et al (2012). Study of promoter methylation pattern of 14-3-3 sigma gene in normal and cancerous tissue of breast: a potential biomarker for detection of breast cancer in patients. Adv Biomed Res, $\mathbf{1}, 80$.

Gypas F, Bei ES, Zervakis M, et al (2011). A disease annotation study of gene signatures in a breast cancer microarray dataset. Conf Proc IEEE Eng Med Biol Soc, 2011, 5551-4.

Hamamori Y, Sartorelli V, Ogryzko V, et al (1999). Regulation of histone acetyltransferases $\mathrm{p} 300$ and PCAF by the bHLH protein twist and adenoviral oncoprotein E1A. Cell, 96, 405-13.

Henrique R, Costa VL, Cerveira N, et al (2006). Hypermethylation of Cyclin D2 is associated with loss of mRNA expression and tumor development in prostate cancer.J Mol Med (Berl). 84, 911-8.

Jentzmik F, Krause H, Reichelt U, et al (2012). GSTP1 CpG island hypermethylation for DNA-based detection of occult tumor cells in surgical margins after radical prostatectomy. World J Urol, 30, 541-6.

Jha AK, Nikbakht M, Jain V, et al (2012). p16(INK4a) and p15(INK4b) gene promoter methylation in cervical cancer patients. Oncol Lett, 3, 1331-5.

Jung EJ, Kim IS, Lee EY, et al (2013). Comparison of methylation profiling in cancerous and their corresponding normal tissues from korean patients with breast cancer. Ann Lab Med, 33, 431-40.

Kaczmarczyk G, Lewandowski R, Trautsolt W, et al (2012). Cytological examination of pleural cavity lavage accompanied by the study of gene promoter hypermethylation of $\mathrm{p} 16$ and O6-methylguanine-DNA-methyltransferase genes in diagnostics of non-small cell lung cancer metastatic changes into pleura. Contemp Oncol (Pozn). 16, 322-7.

Khor GH, Froemming GR, Zain RB, et al (2013). DNA methylation profiling revealed promoter hypermethylationinduced silencing of p16, DDAH2 and DUSP1 in primary oral squamous cell carcinoma. Int J Med Sci, 10, 1727-39.

Kornegoor R, Moelans CB, Verschuur-Maes AH, et al (2012). Promoter hypermethylation in male breast cancer: analysis by multiplex ligation-dependent probe amplification. Breast Cancer Res, 14, 101.

Krop IE, Sgroi D, Porter DA, et al (2001). HIN-1, a putative cytokine highly expressed in normal but not cancerous mammary epithelial cells. Proc Natl Acad Sci USA, 98, 9796-801.

Lee JS, Fackler MJ, Lee JH, et al (2010). Basal-like breast cancer displays distinct patterns of promoter methylation. Cancer Biol Ther, 9, 1017-24.

Lehmann U, Celikkaya G, Hasemeier B, et al (2002). Promoter hypermethylation of the death-associated protein kinase gene in breast cancer is associated with the invasive lobular subtype. Cancer Res, 62, 6634-8.

Liu X, Nugoli M, Laferriere J, et al (2011). Stromal retinoic acid receptor beta promotes mammary gland tumorigenesis. Proc Natl Acad Sci U S A, 108, 774-9.

Mehrotra J, Vali M, McVeigh M, et al (2004). Very high frequency of hypermethylated genes in breast cancer metastasis to the bone, brain, and lung. Clin Cancer Res, 10, 3104-9.

Mishra DK, Chen Z, Wu Y, et al (2010). Global methylation pattern of genes in androgen-sensitive and androgenindependent prostate cancer cells. Mol Cancer Ther, 9, 33-45.

Moelans CB, Verschuur-Maes AHvan Diest PJ (2011). Frequent promoter hypermethylation of BRCA2, CDH13, MSH6, PAX5, PAX6 and WT1 in ductal carcinoma in situ and 
invasive breast cancer. J Pathol, 225, 222-31.

Narayan G, Arias-Pulido H, Koul S, et al (2003). Frequent promoter methylation of CDH1, DAPK, RARB, and HIC1 genes in carcinoma of cervix uteri: its relationship to clinical outcome. Mol Cancer, 2, 24.

Noetzel E, Veeck J, Niederacher D, et al (2008). Promoter methylation-associated loss of ID4 expression is a marker of tumour recurrence in human breast cancer. BMC Cancer, 8, 154 .

O'Brien P, Morin P, Jr., Ouellette RJ, et al (2011). The Pax-5 gene: a pluripotent regulator of B-cell differentiation and cancer disease. Cancer Res, 71, 7345-50.

Palmisano WA, Crume KP, Grimes MJ, et al (2003). Aberrant promoter methylation of the transcription factor genes PAX5 alpha and beta in human cancers. Cancer Res, 63, 4620-5.

Panayiotidis MI (2014). Cancer epigenetics as biomarkers of clinical significance. Cancer Lett, 342, 168-9.

Park SY, Kwon HJ, Lee HE, et al (2011). Promoter CpG island hypermethylation during breast cancer progression. Virchows Arch, 458, 73-84.

Peurala E, Koivunen P, Haapasaari KM, et al (2013). The prognostic significance and value of cyclin D1, CDK4 and p16 in human breast cancer. Breast Cancer Res, 15, 5 .

Radpour R, Barekati Z, Kohler C, et al (2011). Hypermethylation of tumor suppressor genes involved in critical regulatory pathways for developing a blood-based test in breast cancer. PLoS One, 6, 16080.

Raffo P, Emionite L, Colucci L, et al (2000). Retinoid receptors: pathways of proliferation inhibition and apoptosis induction in breast cancer cell lines. Anticancer Res, 20, 1535-43.

Sakuma M, Akahira J, Ito K, et al (2007). Promoter methylation status of the Cyclin D2 gene is associated with poor prognosis in human epithelial ovarian cancer. Cancer Sci, 98, 380-6.

Sanchez-Cespedes M, Esteller M, Wu L, et al (2000). Gene promoter hypermethylation in tumors and serum of head and neck cancer patients. Cancer Res, 60, 892-5.

Sturgeon SR, Balasubramanian R, Schairer C, et al (2012). Detection of promoter methylation of tumor suppressor genes in serum DNA of breast cancer cases and benign breast disease controls. Epigenetics, 7, 1258-67.

Suijkerbuijk SJ, van Osch MH, Bos FL, et al (2010). Molecular causes for BUBR1 dysfunction in the human cancer predisposition syndrome mosaic variegated aneuploidy. Cancer Res, 70, 4891-900.

Sung CO, Lee KW, Han S, et al (2011). Twist1 is up-regulated in gastric cancer-associated fibroblasts with poor clinical outcomes. Am J Pathol, 179, 1827-38.

Tan J, Gu Y, Zhang X, et al (2012). Hypermethylation of CpG islands is more prevalent than hypomethylation across the entire genome in breast carcinogenesis. Clin Exp Med, 13, $1-9$

Tuononen K, Tynninen O, Sarhadi VK, et al (2012). The hypermethylation of the O6-methylguanine-DNA methyltransferase gene promoter in gliomas--correlation with array comparative genome hybridization results and IDH1 mutation. Genes Chromosomes Cancer, 51, 20-29.

Umetani N, Mori T, Koyanagi K, et al (2005). Aberrant hypermethylation of ID4 gene promoter region increases risk of lymph node metastasis in T1 breast cancer. Oncogene, 24, $4721-7$.

Vincent TLGatenby RA (2008). An evolutionary model for initiation, promotion, and progression in carcinogenesis. Int J Oncol, 32, 729-37.

Wang YJ, He L, Yuan M, et al (2014). Epigenetic changes of TIMP-3, GSTP-1 and 14-3-3 sigma genes as indication of status of chronic inflammation and cancer. Int J Biol
Markers, 29, 208-14

Wani HA, Beigh MA, Amin S, et al (2013). Methylation profile of promoter region of $\mathrm{p} 16$ gene in colorectal cancer patients of Kashmir valley. J Biol Regul Homeost Agents, 27, 297307.

Weiwei F, Lanlan S, Sijin W, et al (2007). Correlation between $\mathrm{CpG}$ methylation profiles and hormone receptor status in breast cancers. Breast Cancer Research, 9, 1-13.

Wu Y, Elshimali Y, Sarkissyan M, et al (2012). Expression of FOXO1 is associated with GATA3 and Annexin-1 and predicts disease-free survival in breast cancer. Am J Cancer Res, 2, 104-15.

Xu J, Shetty PB, Feng W, et al (2012). Methylation of HIN-1, RASSF1A, RIL and CDH13 in breast cancer is associated with clinical characteristics, but only RASSF1A methylation is associated with outcome. BMC Cancer, 12, 243.

Yamamoto N, Nakayama T, Kajita M, et al (2012). Detection of aberrant promoter methylation of GSTP1, RASSF1A, and RARbeta 2 in serum DNA of patients with breast cancer by a newly established one-step methylation-specific PCR assay. Breast Cancer Res Treat, 132, 165-73.

Yuan N, Meng M, Liu C, et al (2014). Clinical characteristics and prognostic analysis of triple-negative breast cancer patients. Mol Clin Oncol, 2, 245-51.

Zhao YF, Shen SP, Jiang JY, et al (2010). Methylation and expression of gene p16INK4a and RB in breast carcinoma. Zhonghua Bing Li Xue Za Zhi, 39, 377-81 (in Chinese). 